\title{
Demandas políticas e direitos fundamentais: as ambivalências do pluralismo no Estado Democrático de Direito
}

\author{
Political demands and basic rights: the ambivalences of pluralism within the democratic rule \\ of law
}

Leonardo Monteiro Crespo de Almeida*

\begin{abstract}
REFERÊNCIA
ALMEIDA, Leonardo Monteiro Crespo de. DEMANDAS POLÍTICAS E DIREITOS FUNDAMENTAIS: as ambivalências do pluralismo no Estado Democrático de Direito. Revista da Faculdade de Direito da UFRGS, Porto Alegre, n. 47, p. 83-109, dez. 2021. DOI: https://doi.org/10.22456/0104-6594.113272.
\end{abstract}

\section{RESUMO}

O presente artigo busca examinar de que maneira os direitos fundamentais podem ser ferramentas importantes na consolidação jurídica das demandas políticas dos grupos minoritários no contexto das democracias pluralistas. A pesquisa recorre à teoria política de William E. Connolly com o propósito de abordar os direitos fundamentais de uma maneira que os deixe abertos a sucessivas apropriações e redefinições decorrentes dos conflitos políticos. Para além de suportes institucionais que amparam as pretensões políticas dos atores políticos, os direitos fundamentais surgem como elementos que contribuem para uma maior agregação entre demandas distintas, porém conexas. Em última instância, a pesquisa investiga o lugar dos direitos fundamentais no fortalecimento de um imaginário democrático aberto e tolerante.

\section{PALAVRAS-CHAVE}

William E. Connolly. Pluralização. Direitos Fundamentais. Imaginário Democrático.

\begin{abstract}
This article seeks to examine the different strategies where basic rights are employed to legally establish the political demands of minority groups in pluralist democracies. The research adopts the political theory of William E. Connolly as its theoretical reference in order to develop a conception of basic rights that is open to continuous appropriations and redefinitions within political conflicts. Beyond being a relevant institutional support that grounds the political claims of political actors, basic rights are important elements to increase the cohesiveness of distinct, but connected, demands. Lastly, this research investigates the place of basic rights in making the democratic imaginary more open and inclusive.
\end{abstract}

\section{KEYWORDS}

William E. Connolly. Pluralization. Basic Rights. Democratic Imaginary.

\section{SUMÁRIO}

1. Introdução. 2. O Potencial Político dos Direitos Fundamentais. 3. Os Desafios da Pluralização: Agonismo e Democracia em William E. Connolly. 4. Assemblage, Respeito Agonístico e o Papel Estratégico dos Direitos Fundamentais. 5. Conclusão. Referências. Dados da publicação.

\footnotetext{
*Doutor e Mestre em Direito pela Universidade Federal de Pernambuco/UFPE. Bacharel em Filosofia pela Universidade Federal de Pernambuco/UFPE. Professor Permanente do Programa de Pós-Graduação em Direito da Faculdade Damas da Instrução Cristã/FADIC. Tem se dedicado a realizar uma pesquisar interdisciplinar baseada nas relações entre ontologia política, teoria do direito e teoria social, normalmente através do enfoque teórico do pós-estruturalismo francês e de teóricos correlatos.
} 


\section{INTRODUÇÃO}

Os direitos fundamentais não apenas se constituem como uma das principais conquistas políticas da sociedade burguesa, como também proporcionam uma superfície de inscrição para a proposição de novas demandas. Isso significa que novas demandas políticas encontram nessas espécies de direitos uma linguagem que possibilita o reconhecimento institucional daquilo que está sendo perseguido pelos diferentes atores políticos, como movimentos sociais, partidos políticos ou mesmo indivíduos atuando isoladamente.

Na dinâmica dos direitos fundamentais, portanto, encontra-se em jogo a relação mesma entre o político e o jurídico, principalmente na maneira como um desses polos interfere e transforma o outro. Se os direitos fundamentais asseguram não somente prerrogativas indispensáveis para o advento e a consolidação da participação cidadã nas democracias, eles possibilitam estratégias de contestação do status quo voltadas para a expansão dos direitos e das garantias já estabelecidos. Para além do substrato jurídico, que engloba de maneira decisiva essas formas de mobilização, o que frequentemente se tem é um choque de visões de mundo, de imaginários com sensibilidades e perspectivas distintas frente à organização do social.

Esses choques se tornam recorrentes com o fortalecimento da fragmentação social. Nessa perspectiva, tensões referentes às práticas religiosas, ideologias políticas e conflitos baseados no gênero ou na etnia passam a integrar o cotidiano das diversas democracias ocidentais. Diante desse panorama, a tolerância, enquanto virtude política e fundamento filosófico, passa a ser repensada, sobretudo, com relação aos seus limites e possibilidades: onde estabelecer a linha que separa as posturas e visões de mundo que, diferentes entre si, por isso mesmo contribuem para uma democracia mais vibrante e marcada pela pluralidade de perspectivas, e aquelas posturas que, por sua vez, ameaçam os valores e as estruturas básicas de uma sociedade democrática.

Se a afirmação de que a tolerância exige intolerância com os intolerantes pode, hoje, ser vista como lugar comum, ela é insuficiente para fornecer qualquer espécie de referencial normativo ou valorativo que permita efetuar a distinção entre o que é democraticamente aceitável e inaceitável, como os recentes movimentos autoritários que marcaram algumas das principais democracias ocidentais, como a dos Estados Unidos. A ascensão de novos e diversos focos de conflito fazem com que o sentido da tolerância seja confrontado e trazido ao primeiro plano em um contexto no qual o apelo aos valores transcendentes e invariantes se mostra insuficiente para a manutenção de uma coesão social mais duradoura. Não somente a 
multiplicidade de perspectivas é um forte obstáculo a esse empreendimento, como também as pretensões metafísicas desse apelo são alvo de ampla desconfiança, remetendo a uma época na qual a reflexão filosófica era vista como um acesso privilegiado à verdade e a um saber mais profundo.

O objetivo desse artigo reside em propor, no que diz respeito à investigação sobre direitos fundamentais, uma análise do pluralismo democrático que contribua para a expansão e o fortalecimento desses direitos, ao mesmo tempo em que reconhece a ausência de fundamentos últimos através dos quais os valores subjacentes às demandas políticas possam ser justificados. Um pluralismo estabelecido dessa maneira se estabelece como contingente, reformulável e precário: a cada embate ideológico ou momento de tensionamento político das relações sociais, os sentidos do pluralismo, da tolerância e de valores políticos como liberdade ou igualdade, encontram-se continuamente sendo reconsiderados.

Para fins de alcançar esse objetivo, a pesquisa recorre aos conceitos de respeito agonístico e pluralismo tal como se encontram presentes na teoria política de William E. Connolly. A opção por esse marco teórico reside na maneira como o teórico de John Hopkins concebe o pluralismo, a tolerância e o conflito sem, entretanto, recorrer a algum tipo de fundamentação transcendente e que extrapola os contextos específicos nos quais os sentidos desses termos se encontram confrontados.

Este trabalho é estruturado da seguinte forma. Na primeira seção, pretende-se acentuar a dimensão política e contestadora dos direitos fundamentais, tendo em vista a maneira como eles podem contribuir para uma reformulação, por vezes significativa, dos direitos até então disponíveis. A segunda seção será dedicada a apresentar os aspectos da teoria política de William E. Connolly que são mais pertinentes para o desenvolvimento teórico dessa pesquisa. $\mathrm{Na}$ terceira e última seção, o foco será em conceber politicamente os direitos fundamentais a partir da perspectiva teórica apresentada por Connolly, especialmente no tocante ao pluralismo.

A pesquisa adota como metodologia uma revisão de literatura cujo fio condutor, no que diz respeito à teoria política de Connolly, são as noções de respeito agonístico e de pluralismo, esta última amplamente examinada em livros como The Ethos of Pluralization e Pluralism. No que diz respeito à perspectiva política dos direitos fundamentais, os trabalhos de Costas Douzinas referente aos direitos humanos, sobretudo na obra The End of Human Rights e na coletânea The Meaning of Rights servem como fonte de inspiração e como principal referência para a abordagem dessa temática. 


\title{
2 O POTENCIAL POLÍTICO DOS DIREITOS FUNDAMENTAIS
}

Em The End of Human Rights, Costas Douzinas observa que, na gênese dos direitos humanos, buscou-se elaborar um conjunto de direitos comprometidos com a erradicação de diferentes circunstâncias de exploração e dominação presentes no período moderno conhecido como Iluminismo. Como produto das lutas do seu tempo, os direitos humanos representavam os anseios, as expectativas e o potencial emancipatório presente nos escritos dos autores iluministas, assim como nas diferentes reivindicações da classe burguesa logo se tornou ascendente (DOUZINAS, 2000, p. 1 e ss).

O autor aponta para a centralidade do direito na formação da sociedade moderna, sobretudo como um fator de ruptura frente às formações sociais anteriores. Em diferentes aspectos da cultura moderna, a exemplo do lugar concedido à moralidade e às regras jurídicas técnicas, o direito substitui os mecanismos prévios de integração social. Escreve Douzinas:

\begin{abstract}
[a] centralidade do direito para a cultura moderna é aparente em vários níveis: na substituição da ideia de boa vida pela ideia de direito, de uma vida em conformidade com as regras; na pretensão de que o Estado de direito vai pacificar os conflitos sociais e políticos ao transformá-los em disputas técnicas acerca da interpretação e da aplicação de regras jurídicas confiadas aos especialistas; no esvaziamento da moralidade, que se converte em um domínio privado de convicções 'subjetivas' conflitantes arbitradas pelas regras públicas e 'objetivas' do direito; na ênfase atribuída à forma e ao procedimento (DOUZINAS, 2005, p. 52). ${ }^{1}$
\end{abstract}

Uma vez compreendidos os direitos fundamentais como direitos humanos positivados nas Constituições contemporâneas, esse potencial disruptivo é também preservado na dinâmica de sua operacionalização. Enquanto garantias jurídicas constitucionalizadas, eles estabelecem compromissos normativos profundos entre a autoridade estatal e a população em geral. Ao mesmo tempo em que esse modo de vinculação restringe e organiza o poder da autoridade política frente aos cidadãos, propondo um conjunto de permissões e restrições, essas garantias, por sua vez, viabilizam formas de organização e contestação que permitem a problematização das condições sociais presentes.

Em momentos de crise, o fosso entre as condições atuais e as possibilidades futuras é trazido à tona, disputado e investigado por forças situadas em espectros políticos opostos. É

\footnotetext{
${ }^{1}$ No original: "The centrality of law for modern culture is apparent at various levels: in the replacement of the idea of good life by that of right, of life according to rules; in the claim that the rule of law will pacify social and political conflict by turning it into technical disputes about the interpretation and application of legal rules entrusted in the hands of rule experts; in the hallowing out of morality which has been turned into a private domain of conflicting 'subjective' convictions arbitrated by the 'objective' and public rules of law; in the emphasis placed on form and procedure."
} 
neste ponto que a atividade crítica se mostra decisiva e recorrente nas preocupações de diferentes segmentos do social: o momento presente é confrontado a partir dos potenciais implícitos na estrutura social presente. Um dos pontos que conduz a atividade crítica é a seguinte: trazer à tona transformações que tornem concretos uma parte desses potenciais. Acerca dessa temática, Costas Douzinas escreve:

[a] crise fornece a distância ou a lacuna necessária entre o pensamento e aquilo que pelo qual faz a crítica emergir. Como incitadora ou resultante da crise, a crítica se distancia do existente; ela se distingue por uma certa gravidade, sendo penetrante, mas também enunciadora de problemas (DOUZINAS, 2005, p. 48). ${ }^{2}$

Ao mesmo tempo em que penetra em uma circunstância contemporânea, a crítica a converte em um problema, ou seja, em uma questão que espera, por vezes desesperadamente, por uma resposta, seja na forma de construção teórica ou intervenção prática. A imaginação política remete ao intrincado trabalho não apenas contestatório, mas também criativo de se pensar em outros arranjos e dinâmicas institucionais viáveis. Essa é uma questão prontamente perceptível quando observada a atuação dos movimentos sociais e a implementação das suas estratégias políticas. O movimento em defesa dos direitos civis (civil rights movement) nos Estados Unidos lutou para que os direitos constitucionalmente assegurados fossem expandidos para a população negra.

A atitude crítica não ocorre tão somente no nível mais concreto e imediatamente perceptível do cotidiano, contemplando também a dimensão mais profunda das ideias e dos fundamentos subjacentes ao imaginário político dos Estados Unidos. No caso do movimento em defesa dos direitos civis, não somente a atuação de certas instituições confrontou-se a dinâmica de certas organizações, como a atuação da polícia, a segmentação das escolas e dos transportes, como também do ideal de igualdade que permeava até então o imaginário político do país e consequentemente também de sua democracia (ALEXANDER, 2017, p. 201 e ss). O ideal da terra da prosperidade na qual distinções familiares ou étnicas eram pouco relevantes frente à utilidade do que os indivíduos poderiam contribuir é diretamente confrontado pela intervenção do movimento e dos seus líderes.

Ao estabelecerem compromissos normativos, os direitos fundamentais operam a partir de uma dupla temporalidade: eles realizam uma intervenção no panorama presente, ao mesmo tempo em que propõem uma projeção futura particular, não inteiramente compatível com as

\footnotetext{
${ }^{2}$ No original: "Crisis offers the necessary distance or gap between thought and the given from which critique emerges. As the prompter or the result of crisis, critique was a turning away from the existent; it was distinguished by a certain gravitas, it cut away but also spelled trouble."
} 
circunstâncias presentes. É a partir dessas projeções que os diferentes movimentos sociais contestam a ordem presente a partir dos próprios valores estabelecidos ao invés de se insurgirem contra eles.

A igualdade, portanto, deixa de ser uma ideia ou um valor abstrato, importante, porém desconectado da realidade institucional, para ser não apenas um compromisso firmado entre a autoridade estabelecida e os seus subordinados, como também uma garantia cujo sentido mais profundo se encontra em contínuo deslocamento. Em outras palavras, o sentido da igualdade se encontra continuamente reformulado em meio aos diferentes tensionamentos políticos marcados pela presença de demandas variadas e concorrentes. É disso que se trata o potencial político dos direitos fundamentais: ao mesmo tempo em que se encontra enraizado no ordenamento jurídico estabelecido, podendo ser operacionalizado nas circunstâncias presentes por aqueles que deles necessitam, na forma de garantia os direitos fundamentais, fornecem horizontes e superfícies de inscrições, projeções para um futuro sempre adiado.

Esse futuro sempre adiado representa, também, um ponto no qual convergem a atividade crítica e uma práxis social que traz consigo uma dimensão experimental: jamais é possível controlar por completo quais as consequências de cada um desses direitos, o que inclui as possibilidades de sua operacionalização em contextos políticos muito distintos. Esse potencial expansivo dos direitos fundamentais remete a uma criatividade incessante, imprevisível e disruptiva: já não é possível antecipar de antemão quais serão os focos de conflito nos quais os direitos fundamentais serão operacionalizados e redefinidos em seus usos e sentidos. A contestação levada adiante pela atividade crítica remete a uma incessante politização do social na qual cada segmento, outrora percebido em termos naturais e objetivos, é agora abordado como produto de práticas culturais e/ou reflexo direto de interesses e estratégias ideológicas particulares.

Atitudes e comportamentos outrora banalizados ou até objetos de alívio cômico, a exemplo da prática do blackface no entretenimento dos Estados Unidos ou das situações cotidianas de assédio que uma considerável parte das mulheres que adentraram no mercado de trabalho nas décadas de sessenta e setenta tiveram que suportar para ascender profissionalmente, hoje, são envolvidos por expressiva reprovação social ou são ilícitos penais. Transformações como essa são frutos de uma politização do social através de uma conscientização mais aguda quanto às relações de dominação e opressão: essas práticas gradualmente são percebidas como incompatíveis, senão opostas, aos ideais materializados no imaginário político das democracias liberais amplamente compartilhado e alimentado. 
Essa conscientização, que emerge de muita dor e sofrimento silencioso dos segmentos oprimidos, é frequentemente desenvolvida a partir da formulação de demandas políticas e reinvindicações jurídicas que simultaneamente expõem e problematizam as relações assimétricas estabelecidas pelo status quo, inclusive recorrendo aos direitos naturais como amparo retórico que justifique essas relações (PARTHEMOS, 1962, p. 100). É no decorrer da luta que os mencionados referenciais valorativos passam por transformações importantes: a igualdade, por exemplo, outrora pensada a partir de contextos laborais ou políticas de redistribuição de renda, passa a ser articulada a contextos nos quais as relações assimétricas entre gêneros criam problemas profundos para a parte mais frágil, como dificuldade de acessar o mercado de trabalho ou nele progredir, participação efetiva em comitês de decisão, representação política, dentre outros.

Mais do que reconsiderar criticamente as representações femininas no espaço social por meio da formulação de demandas políticas, crítica cultural e reinvindicação jurídica, as diferentes gerações dos movimentos feministas também mostraram as interseções entre gênero, opções profissionais, renda familiar e graus de independência financeira. As intersecções ilustram o grau de complexidade das diferentes assimetrias que perpassam o social: não se mostram prontamente perceptível os impactos e as consequências causadas pelas disparidades e como uma assimetria tende a impactar a outra.

Em direção semelhante, o valor da liberdade, como conhecidamente observou Isaiah Berlin, pode ser envolvido por um sentido existencial mais amplo no qual a autonomia seja central: o que está em jogo, no contexto feminino, por exemplo, seria um maior espaço para que as mulheres concretizem seus diferentes projetos existenciais sem que sejam confrontadas ou obstruídas em suas pretensões (ALVAREZ, 2009, p. 130 e ss; SILVA, 2005, p. 245 e ss). Implica, portanto, uma maior flexibilidade em desenvolver os seus itinerários, as suas pretensões, os valores mais alinhados às suas sensibilidades. Ao invés de uma existência que se desdobra em conformidade com os interesses do status quo, a liberdade sinaliza um domínio no qual as mulheres podem ser artistas que cultivavam a sua existência singular como obra de arte irrepetível (CORNELL, 1998, p. 176 e ss).

Uma liberdade pensada dessa forma está distante, porém, não é contraditória com aquela, mais usual, referente às liberdades de expressão, de pensamento ou mesmo da livreiniciativa. Ao mesmo tempo em que envolve todas elas, essa concepção de liberdade acentua a possibilidade de uma redefinição incessante da imagem que se tem sobre si mesma e que, em larga medida, fora socialmente construída e imposta. Isso remete ao que Drucilla Cornell e 
muito da filosofia política contemporânea tem discutido há algumas décadas como a separação entre direito (right) e bom (good) (CORNELL, 1998, p. 176 e ss).

Essa distinção propõe uma separação entre o sistema de direitos do conjunto e as convicções morais muito particulares em torno da maneira mais correta de se conduzir a vida. Isso pode implicar em reconsiderar a liberdade, que agora se envolve com a imaginação e a autodeterminação referente às possibilidades existenciais de cada um, e a igualdade como uma igual distribuição de direitos. Abordando essa temática no âmbito das relações de gênero, Cornell observa:

[a] separação do direito do bom é fundamental para o reconhecimento da igualdade de nossa personalidade porque nossas mais profundas convicções sobre o que é sexualmente certo para nós podem nos levar na direção de pensar que o nosso caminho é o único caminho. Um casal de lésbicas que pretende ter uma criança não interfere de modo algum no direito do casal heterossexual em também criar uma; ao invés disso, ambos os casais deveriam ter o direito para estabelecer as suas vidas íntimas da maneira que eles imaginem que é o melhor para eles (CORNELL, 1998, p. 176-177). ${ }^{3}$

Ao mesmo tempo em que podem ser abordados como expressão direta das formações ideológicas, os direitos fundamentais fornecem uma linguagem institucionalizada por meio da qual demandas políticas podem ser diretamente traduzidas na linguagem institucionalizada das normas jurídicas. Para além da força simbólica que emerge da fundamentação das demandas a partir das normas jurídicas, também é importante destacar que esse processo frequentemente implica em estratégias de apropriação e reinterpretação dos textos constitucionais e outros diplomas normativos de considerável importância.

\section{OS DESAFIOS DA PLURALIZAÇÃO: AGONISMO E DEMOCRACIA EM WILLIAM E. CONNOLY}

Um dos aspectos mais persistentes das democracias contemporâneas é a ampla diversidade dos segmentos constitutivos do seu tecido social: a ideia de um ethos uniforme, no qual os indivíduos tendem a compartilhar um mesmo credo, conjunto de valores ou referenciais políticos, cede espaço para uma realidade plural, multifacetada, na qual a diferenciação entre

\footnotetext{
${ }^{3}$ No original: "The separation of the right from the good is crucial for the recognition of our equal personhood precisely because our own deeply held convictions about what is good for us sexually may push us in the direction of thinking that our way is the only way. A lesbian couple taking on parenting does not in any way interfere with a heterosexual couple's right to parenthood; rather, both couples should have the right to set up their intimate lives in the way they imagine is best for them."
} 
elas é contínua e cada vez mais ampla. É também por conta dessa configuração que o núcleo central da sociedade democrática é esvaziado de qualquer substância essencial e persistente.

Na conhecida observação de Claude Lefort, a democracia moderna é marcada por um lugar vazio do poder, cujo preenchimento somente poderá ser precário e contingente (LEFORT, 1988, p. 17 e ss). Neste panorama ilustrativo, o que se tem é uma sociedade cujo fundamento é translúcido, carente de uma figura decisiva que fundamentaria a estrutura social, como fora o monarca. Em outras palavras, qualquer concepção que se torne majoritária, assim o será provisoriamente, ou seja, até que uma outra apareça e lhe substitua. Pode-se dizer que o traço distintivo da democracia moderna, pós-revolução francesa, é de que o seu fundamento é perpassado por uma relação diferencial persistente que só pode ser parcialmente estabilizada por meio de posições que contam com uma maior abrangência e adesão por parte dos indivíduos (SILVA, 2005, p. 545 e ss).

Em diferentes obras, como The Ethos of Pluralization, Identity/Difference e Pluralism, o teórico político William E. Connolly tratou de investigar não apenas os diferentes significados do pluralismo que integram uma certa tradição política e filosófica, como a potencialidade para um alargamento ou aprofundamento do imaginário democrático nas sociedades contemporâneas. É preciso compreender como os paradoxos e as ambivalências que marcam o pluralismo também formam espaços de resistência às diferentes formas de autoritarismo e de exploração que emergem no panorama moderno e persistem até os dias atuais. Se valores como liberdade e igualdade, sobretudo em suas acepções jurídicas, são esvaziados de quaisquer resquícios de essencialismo, os seus sentidos emergem dos sucessivos movimentos de apropriação nos discursos e nas estratégias políticas constitutivas dos diferentes segmentos do social.

Em The Ethos of Pluralization, Connolly aponta como a redução da desigualdade social é um ponto crucial para o fortalecimento do dinâmica de pluralização democrática. $O$ valor da igualdade, neste ponto, é amplo o suficiente para amparar formas de controle da economia de mercado, de redistribuição dos recursos materiais da sociedade para os membros mais carentes, como também outros mecanismos de inclusão social. Entretanto, é importante reconhecer que essa tendência precisa ser justaposta à preocupação de se proteger a diversidade presente nos arranjos culturais já existentes. Trata-se da consciência de que a defesa da igualdade como um fim em si mesmo pode acarretar um maior déficit, ao invés de fortalecimento dos impulsos de pluralização que envolvem e norteiam o imaginário político das democracias liberais. Connolly observa: 
[u]ma redução expressiva na desigualdade econômica é muito importante para uma democracia robusta. Mas um tal projeto precisa ser conduzido de modo a não enfraquecer tanto o pluralismo cultural existente ou possibilidades futuras de pluralização democrática: a igualdade precisa ser vista não apenas como um fim em si mesmo, mas também como condição para a pluralização democrática (CONNOLLY, 1995, p. 80). ${ }^{4}$

Considerando as necessidades sociais básicas presentes nas democracias liberais contemporâneas, o objetivo decisivo da igualdade econômica é estabelecer um patamar tal que os cidadãos disponham dos serviços e condições fundamentais, uma reconsideração incessante da economia de mercado se torna, neste ponto, decisiva. Neste contexto, portanto, uma consideração da igualdade exclui um retorno às economias de mercado planificadas, características das nações socialistas do século XX, uma vez que a grande diversidade das necessidades sociais e a própria complexidade do capitalismo tornam de difícil implementação um amplo e incisivo controle sobre os mercados (CONNOLLY, 1995, p. 80-81).

Um ponto que precisa ser observado nesta questão é que a pluralidade de identidades políticas não necessariamente implica em um maior potencial de inclusão social e econômica. Espaços sociais marcados por uma ampla diversidade, a princípio, podem ser caracterizados como pluralistas, mas essa caracterização ignora certos aspectos políticos importantes. Além disso, os impulsos por pluralização podem ser concorrentes: a promoção da igualdade entre os sexos, por exemplo, torna difícil limitar a intervenção estatal no ambiente familiar em que a figura masculina, em um contexto patriarcal, se mostrou central (CONNOLLY, 2008, p. 175 e ss). O primeiro deles é que as diferenças podem não ser - e frequentemente não o são concebidas a partir de um eixo horizontal no qual todas elas integram um mesmo plano. Com efeito, os diferentes recortes políticos realizados sobre o espaço social tendem a elencar certas identidades e projetos políticos como sendo moralmente superiores e mais desejáveis do que outros.

Sendo assim, uma comunidade marcada pela pluralidade de religiões pode muito bem eleger uma ou duas delas como sendo aquelas que expressam formas de vida desejáveis ao mesmo tempo em que relega as outras religiões a uma condição periférica, uma em que o sistema de direitos positivados é insuficiente para proteger as suas prerrogativas mais fundamentais. Vítimas da violência intolerante, as religiões minoritárias, por vezes, carecem

\footnotetext{
${ }^{4}$ No original: "A significant reduction in economic inequality is surely crucial to a robust democracy. But such a project must be pursued in ways that do not undermine either existing cultural pluralism or future possibilities of democratic pluralization: equality must be viewed not simply as an end in itself but also as a condition of democratic pluralization."
} 
dos espaços políticos que as permitiriam trazer à tona as suas necessidades para assim ampliar os direitos disponíveis. Sem apoio econômico do Estado ou inviabilizadas de obtê-los, elas aos poucos deixam de existir.

Pluralidade, portanto, não significa necessariamente a adesão de valores que fomentam uma visão de mundo pluralista, expansiva, marcada pela diferença: sinaliza tão somente um espaço social fragmentado por manifestações culturais e perspectivas político-ideológicas distintas. É preciso verificar, porém, como o aparato institucional e as forças políticas hegemônicas concebem essa pluralidade, seja ela como um aspecto que tende a fortalecer o imaginário democrático da comunidade ou como um empecilho à concretização dos valores adotados por essas forças.

É por essa razão que é importante não considerar apenas a diversidade presente em um determinado estado de coisas, mas os diferentes vetores que tendem a contribuir para a expansão dessa diversidade ou que levam ao seu próprio retraimento. É recorrendo ao conceito de pluralização que Connolly busca apontar para essas tendências variadas (CONNOLLY, 1995, p. 37 e ss). Considerando que as lutas sociais tendem a fomentar um movimento incessantemente disruptivo das identidades e grupos políticos, movimento este que coloca em questão os costumes, tradições e valores, a sociedade é politicamente reorganizada a partir de novos referenciais ideológicos. Pode-se dizer que a identidade só existe e somente se mantém a partir de uma relação diferencial com o Outro que lhe extrapola (CONNOLLY, 2008a, p. 147).

É neste ponto que surge, no cerne das democracias liberais, a pergunta acerca dos limites da tolerância: até onde vai esse limite? Quais demandas podem ser consideradas legítimas, válidas, frutos das limitações do sistema jurídico, da apatia da política institucionalizada e/ou das ineficiências do mercado? Quais, por outro lado, colocam em risco cada uma das conquistas históricas que levaram à formação do Estado de Direito e à implementação das democracias liberais? Mais do que estabelecer a tolerância como um conceito marcadamente político, a pluralização também a torna um conceito politicamente problemático, cujo sentido é objeto de constantes negociações em meio ao desenvolvimento de posições abrangentes e hegemônicas, algo que Chantal Mouffe sinaliza com grande proximidade às reflexões suscitadas por Connolly (MOUFFE, 2014, p. 181 e ss). No que diz respeito à tolerância e aos outros valores presentes em uma dada tradição democrática, é importante pensar o entrelaçamento do universal, abrangente, com o particular específico apresentado pela experiência social de cada identidade política. 
Circunstâncias de tolerância em contextos pluralistas normalmente envolvem dilemas e oposições que não podem ser resolvidas a partir de uma referência a uma única escala de valores capazes de determinar a solução correta ou mais aceitável para o impasse. A incomensurabilidade marca, sobretudo, essa impossibilidade de se chegar a uma decisão definitiva entre valores concorrentes (ALVAREZ, 2009, p. 127 e ss).

As posições abrangentes apontadas no parágrafo precedente apontam para o esforço e a necessidade de se transcender às perspectivas particulares que tendem a nortear as ações, sensibilidades e pensamentos dos atores políticos (MAVELLI, 2009, p. 148 e ss). Elas implicam um esforço de universalização que, entretanto, dispensa a fundamentação metafísica e as pretensões essencialistas que historicamente caracterizaram esse tipo de movimento. Uma assemblage $^{5}$, por mais ampla e influente que possa ser em um determinado espaço social, é sempre contingente e precária, podendo deixar de existir a cada nova situação: uma universalidade que se estabelece a partir desse tipo de formação expressa mais um esforço de transcendência em meio a uma concepção imanente do social do que uma perspectiva, ou ponto de vista, dissociada das tensões e dos conflitos que atravessam a ordem social (WENMAN, 2008, p. 164 e ss). A importância política da contingência não escapou a Connolly, que muito se debruçou sobre ela em sua obra tardia (VALENTINE, 2009, p. 205 e ss).

O estabelecimento de posições abrangentes, no entanto, exige uma delimitação do espaço social entre formações ideológicas que são compatíveis com essas posições majoritárias e aquelas que, sendo incompatíveis, representam também obstáculos à sua expansão e concretização. Connolly concebe essas posições abrangentes e que se estendem pelo espaço social em termos de assemblages democráticas: essas assemblages representam agregados cujas relações entre as suas partes são estabelecidas em termos contingentes e circunstanciais. Não são, portanto, totalidades que subsumem as suas partes, alterando os seus elementos constitutivos, mas redes heterogêneas que permitem associações organizadas em termos de aproximação e semelhança, como de oposição. Em uma passagem do seu artigo The Ethos of Democratization, Connolly destaca a heterogeneidade constitutiva que marca essas posições abrangentes:

[a] assemblage política que eu busco, por exemplo, incorporaria alguns participantes porque ela atende as suas necessidades mais urgentes; outros em função de interesses econômicos mais sutis; outros porque participam da identidade por meio de assemblages em torno da religião, da etnicidade, sexualidade e gênero; outros por

${ }^{5}$ Para uma abordagem mais densa desse conceito em termos de teoria ou filosofia social, Cf. DELANDA, 2016; DELANDA, 2019. 
conta de compromissos éticos não-teísticos ou religiosos que os levam a se preocupar para além das suas próprias necessidades, interesses e identidades constitutivas; outros ainda porque temem que o aumento da criminalidade e tumultos urbanos venham a subverter a sua qualidade de vida, e a maioria por conta de uma combinação de algumas dessas preocupações (CONNOLLY, 2004, p. 168). ${ }^{6}$

A variedade de interesses e necessidades que constituem a assemblage política faz com que a sua existência dependa de uma manutenção constante do ethos que lhe originou e que opera uma conexão entre esses diferentes pontos (CONNOLLY, 2008b, p. 236). Idade, sexualidade, gênero, cultura, classe econômica e social constituem dimensões e pontos de conexão que permitem agregar, articular ou dissociar um conjunto de atores políticos: são propriedades que acompanham os indivíduos em seu engajamento pré-teórico com o mundo e, portanto, enquadram a maneira como a realidade social é apreendida por cada um deles (CONNOLLY, 2008c, p. 86 e ss). Essas conexões, porém, não decorrem de interesses profundos ou disposições naturais ancoradas na essência, ou seja, no conjunto de propriedades persistentes de cada um desses atores jurídicos: não só essas conexões precisam ser construídas a partir de circunstâncias singulares, como elas também são, por essa razão, contingentes e precárias.

Contingência e precariedade, neste contexto, expressam não somente a ausência de necessidade subjacente às conexões formadas, como também de sua inerente incompletude: uma vez que as diversas condições que concorrerem para a formação dessas conexões deixem de existir no espaço social, a assemblage pode ser também desfeita, com cada ator político seguindo direções específicas e não mais alinhadas entre si. Por essa razão é importante explorar quais elementos contribuem para tornar uma assemblage persistente. Cada assemblage traz consigo uma série de valores, de referenciais e de critérios que, por mais elusivos e variados que sejam os seus sentidos, são também pontos que solidificam a conexão entre esses interesses e necessidades variadas. Os diferentes aspectos que envolvem a existência social dos indivíduos, abrangendo desde idade até etnicidade e gênero, são fundamentais para a organização das assemblages e o desenvolvimento de um ethos abrangente que lhe será característico. Em seu artigo The Ethos of Democratization, ao mencionar o tipo de assemblage hegemônica que ele tem em mente, Connolly observa:

\footnotetext{
${ }^{6}$ No original: "The political assemblage I pursue, for instance, would incorporate some participants because it speaks to their desperate needs; others because of more composed economic self-interest; others because of participation in identities supported by the assemblage in religion, ethnicity, sexuality, or gender; others because of religious or nontheistic ethical commitments that inspire them to extend beyond their own constituency needs, interests, and identities; others yet because they fear rises in the rate of crime and urban unrest that would otherwise undermine their quality of life, and most because of some combination of these concerns."
} 
[a] assemblage hegemônica que buscamos será desenvolvida a partir de várias posições de sujeito nos domínios da classe econômica, religião, idade, nível educacional, etnicidade, gênero e afiliações sensuais. A consolidação dessa assemblage está muito associada à sensibilidade e ao ethos que os seus participantes trazem para a relação entre eles e com os outros (CONNOLLY, 2004, p. 168). ${ }^{7}$

Uma assemblage democrática, por exemplo, vai emergir não apenas através das diferentes redes de conexão e aproximação entre as suas posições constitutivas, como também por meio de relações de oposição com outras assemblages marcadas por direcionamentos opostos. O desenvolvimento de critérios normativos que estabelecem quais posições devem ser toleradas e quais representam um risco só podem ser articulados aqui a partir de uma ou outra assemblage: na abordagem de Connolly, não existe qualquer posição transcendente que permita a elaboração de critérios dissociados das perspectivas específicas e circunstanciais dos atores políticos. Cada critério ou conceito, para além de ser politicamente contestável, é também precário, logo, suscetível a contínuas reformulações.

Esse trabalho de redefinição incessante do panorama político da democracia reflete bem o que Claude Lefort chamou de lugar vazio do poder no que diz respeito à formação histórica das democracias modernas (LEFORT, 1988, p. 17 e ss). Esse vazio nem pode ser apreendido a partir de qualquer posicionamento político ou formação ideológica, nem pode ser definitivamente determinado por qualquer força política, por mais consolidada que sejam as suas ideias, valores e crenças no âmbito do espaço social.

Assumindo não somente que esses compromissos normativos carecem de uma fundamentação transcendente e que hoje existem diversas concepções, inclusive concorrentes, sobre a vida correta, a estratégia de Connolly, então, é pensar o aprofundamento das democracias mediante a expansão e a intensificação de um ethos específico a partir do que ele vai chamar de assemblage democrática. O pluralismo das formas de vida sociais é reconhecido, mas a sua expansão depende também do reconhecimento daquilo que lhe extrapola e que lhe nega, ou seja, das formas de vida antidemocráticas. É essa exterioridade negativa, que estabelece uma oposição de valores e de imaginários, que permite uma continuidade persistente de uma assemblage que vai se estabelecer hegemonicamente, ou seja, de modo mais expansivo. Por isso a fixação de um ethos é tão importante na constituição das assemblages: é por meio

\footnotetext{
${ }^{7}$ No original: "The hegemonic assemblage we seek will be drawn from several subject positions in the domains of economic class, religion, age, education level, ethnicity, gender, and sensual affiliation. Whether such an assemblage becomes consolidated has a lot to do with the sensibility and ethos its participants bring to relations between themselves and with others".
} 
dela que a fronteira entre o interior e o exterior é demarcada e continuamente renegociada em meios às transformações do espaço social.

Isso não significa de modo algum que certas cisões ou direcionamentos contraditórios não possam se desenvolver no interior de cada assemblage. Uma dessas situações pode ser observada na tensão que Joanildo Burity aponta entre os discursos que simultaneamente reconhecem e promovem as diferenças, como a religiosa, mas que também são marcados pela desconfiança de que a participação política, na arena pública, de identidades manifestamente religiosas implica colocar em risco, em diferentes graus, a própria laicidade do Estado de Direito e, desta maneira, mais adiante podem surgir direitos como os de liberdade de expressão ou de religião. Burity escreve:

[c]omo isso rebate sobre a questão da agência religiosa na conjuntura atual? Bem, primeiramente, em nome do republicanismo, reacende-se a desconfiança de que a presença religiosa na esfera pública a enfraquece, pois introduz uma lógica particularista no lugar onde só deveria prevalecer o interesse de toda a sociedade. Segundo, tal presença agrediria um pilar do republicanismo, que é a laicidade do Estado (BURITY, 2008, p. 89).

O tipo de ethos que Connolly vai atribuir a uma assemblage democrática envolve o cultivo de certas virtudes que se fazem importantes para o fortalecimento do imaginário democrático em panoramas marcados por um amplo grau de pluralismo. Apesar das dificuldades semânticas significativas que acabam por envolver o conceito de ethos na teoria política de Connolly, o seu uso remete à importância de se construir uma perspectiva mais abrangente, universal, sendo capaz de fomentar interseções e estratégias entre os diferentes grupos.

Essa tarefa é acompanhada por uma série de dificuldades, mas sem dúvida uma das que vai recair mais significativamente nas diferentes formas de ressentimento que envolvem cada posição particular. Compreende-se por ressentimento, neste panorama teórico, todo o conjunto de necessidades, restrições e obstáculos que tendem a fazer com que cada grupo se mostre fixado nas suas lutas e reivindicações específicas, ignorando ou minimizando o panorama sociopolítico mais abrangente que os envolve. É importante reconhecer que, ao mesmo tempo em que os grupos se recusam a deixar as suas mais profundas convicções particulares no âmbito privado ao adentrarem nos espaços públicos, é importante que esse tensionamento entre as convicções seja capaz de produzir alternativas que viabilizem a superação dos impulsos de ressentimento que levam os grupos a ficarem circunscritos às restrições das suas condições. Escreve Connolly sobre essa questão: 
[o] objetivo é desenvolver um ethos entre um conjunto de elementos interdependentes que dificilmente vão deixar as suas convicções no espaço privado quando adentram na política ou apresentam essa fé de maneira tão incisiva que dificilmente se converte outros que já não compartilhem dessa orientação. Um ethos positivo da política não surge a partir de um princípio austero de justiça ou de uma única lógica de deliberação. Ele se desenvolve a partir de um reconhecimento recíproco do elemento de partidarismo presente em cada orientação sobre uma ética pública ao lado de esforços conscientes das diversas partes em superar o ressentimento existencial desta condição (CONNOLLY, 2004, p. 169). ${ }^{8}$

Transcender os ressentimentos, então, exige uma conscientização de uma orientação partidária que, estendendo-se a todos, também ultrapassa cada demanda particular sem que as suas particularidades e lutas históricas sejam anuladas nesse processo. Alcançar essa orientação envolve não só cultivo de um pensamento estratégico e de sensibilidades que promovam aberturas e conexões mais abrangentes, como também a apropriação de elementos institucionais compartilhados pelas identidades. No tocante ao cultivo das sensibilidades, Connolly desenvolve um conceito cuja importância para a teorização proposta nesta pesquisa é decisiva: trata-se do respeito agonístico, noção também trabalhada por uma outra teórica que reflete sobre esse tema, Chantal Mouffe (2005, p. 29). Algumas razões que fundamentam essa posição seguem abaixo.

Primeiramente, o cerne do respeito agonístico é a consideração do conflito, das tensões existentes entre as diferentes visões de mundo, o que é visto como algo produtivo em vários níveis: essa oposição não é apenas decisiva para a constituição das assemblages coletivas, como faz com que as várias perspectivas sobre uma mesma questão sejam levadas em consideração. Neste processo, as fragilidades, inconsistências e apelos afetivos de cada uma dessas perspectivas são trazidos ao primeiro plano e testados em meio às circunstâncias de embate: o conflito é abordado de uma maneira que reforce a pluralização e as diferenças entre perspectivas. O respeito, neste contexto, significa atribuir ao outro um grau de credibilidade, de sinceridade em suas convicções, ainda que delas se discorde profundamente. É desta maneira que Connolly aborda o conceito:

[o] respeito agonístico é um primo próximo da tolerância liberal. É a relação entre partidários interdependentes que já se encontram em um mesmo registro de reconhecimento cultural. Mas a tolerância liberal é baseada em uma esfera pública

\footnotetext{
${ }^{8}$ No original: "The aim is to fashion an ethos between interdependent constituencies who are unlikely either to leave their partisan faiths in the private realm when they enter politics or to establish it with enough certainty to convince many not already inducted into it. A positive ethos of politics does not grow out of an austere principle of justice or a single logic of deliberation. It grows out of reciprocal appreciation of the element of partisanship in each orientation to public ethics, alongside concerted efforts by numerous parties to overcome existential resentment of this condition".
} 
geral na qual todas as partes compartilham uma orientação abrangente acerca dos raciocínios, dos procedimentos e da deliberação, deixando as suas crenças na esfera privada. A tolerância liberal é, acima de tudo, a tolerância da diversidade privada; ela depende de um acordo deliberativo na esfera pública mais firme do que as pessoas podem fazê-lo no período de modernidade tardia quando a cristandade não mais implementa o pano de fundo estabelecido da vida pública (CONNOLLY, 2004, p. 176). ${ }^{9}$

A segunda razão é a de que a consideração das múltiplas perspectivas permite, por sua vez, situar a maneira como elementos institucionalizados, a exemplo dos direitos fundamentais, podem ser discursivamente redefinidos a partir de cada inserção deles em um tipo de demanda ou pauta política. É neste ponto que o significado de termos como liberdade, igualdade, a própria tolerância, ou o direito à habitação podem adquirir novos contornos e usos que, a princípio, não se faziam disponíveis nos momentos iniciais de sua positivação. $\mathrm{O}$ alargamento ou a redefinição dos valores, para além de se buscar uma justificativa a partir de elementos do direito positivo, expressam a própria estratégia de ampliação dos espaços e reconhecimento das demandas.

Por fim, uma terceira razão para a relevância do respeito agonístico residiria em desconsiderar qualquer forma de transcendência que poderia estar associado a esses direitos em particular. Muito embora a colocação dos direitos fundamentais como conceitos políticos essencialmente contestáveis não seja algo necessariamente associado ao respeito agonístico. Observa-se, antes, a maneira como Connolly aborda os conceitos políticos essencialmente contestáveis:

\begin{abstract}
[q]uando a discordância não reflete simplesmente leituras diferentes de uma evidência a partir de um sistema de conceitos compartilhados, podemos dizer que surge uma controvérsia conceitual. Quando o conceito envolvido avalia o estado de caso que ele mesmo descreve, quando a prática descrita é internamente complexa em que a sua caracterização envolve referências a várias dimensões, e quando as regras de aplicação aceitas e contestadas se encontram relativamente abertas, permitindo que ambas as partes interpretem até mesmo as regras compartilhadas de maneira diferente na medida em que novas e imprevistas situações surgem, então o conceito em questão é um "conceito essencialmente contestado" (CONNOLLY, 2008d, p. 257). ${ }^{10}$
\end{abstract}

\footnotetext{
${ }^{9}$ No original: "Agonistic respect is a kissing cousin of liberal tolerance. It is a relation between interdependent partisans who are already on the register of cultural recognition. But liberal tolerance is predicated upon a general public realm where all parties share a general orientation to reasoning, procedure, and deliberation and where they leave their faiths in the private realm. Liberal tolerance is above all tolerance of private diversity; it depends upon more deliberative agreement in the public realm than people can marshal in a late-modern period when Christendom no longer sets the settled, assured background of public life."

${ }^{10}$ No original: "When the disagreement does not simply reflect different readings of evidence within a fully shared system of concepts, we can say that a conceptual dispute has arisen. When the concept involved is appraisive in that the state of affairs it describes is a valued achievement, when the practice described is internally complex in that its characterization involves reference to several dimensions, and when the agreed and contested rules of application are relatively open, enabling parties to interpret even those shared rules differently as new and unforeseen situations arise, then the concept in question is an "essentially contested concept"."
} 
Uma vez que a multiplicidade de perspectivas é estabelecida em torno de um determinado tema ou conceito, o caráter contestável de cada uma das concepções é trazido também à tona, esclarecendo os seus pontos fracos, as suas inconsistências e outros aspectos que exponham as suas limitações. É neste ponto que os elementos institucionalizados, neste caso, os direitos fundamentais, conectam-se ao respeito agonístico: os direitos, para além de sua eficácia normativa, podem proporcionar uma linguagem compartilhada, ou seja, um pano de fundo simbólico, que forneça pontos de convergência entre as diferentes demandas, além de um suporte institucional que desloque essas demandas para além dos limites da retórica política, ou o que Paul Patton aponta como o caráter a-histórico e universal dos direitos (PATTON, 2014, p. 235). Um maior esclarecimento da relação entre respeito agonístico e a institucionalização dos direitos fundamentais será agora o objeto da terceira seção.

\section{ASSEMblages, ResPeito Agonístico E O PAPEL ESTRATÉgico dos DIREITOS FUNDAMENTAIS}

Na medida em que foi desenvolvido a partir de um panorama teórico muito específico, o conceito de assemblage expressa a maneira com que Connolly aborda as subjetividades políticas coletivas sem, no entanto, recorrer a um sujeito histórico universal, cujas lutas e demandas subsumiriam aquelas outras demandas dos grupos minoritários. Uma vez que se constitui a partir de circunstâncias contingentes, as assemblages podem se desfazer da mesma maneira que vieram a existir: não existe nada de necessário, imutável ou incontornável na sua existência. É também a partir desse referencial que o potencial político dos direitos fundamentais será examinado, a partir dos diferentes focos de conflito e demandas que emergem no panorama social das democracias contemporâneas.

A formação e a manutenção das assemblages depende, em larga escala, do cultivo de determinadas virtudes inscritas em um ethos, sendo uma delas o respeito agonístico. Este respeito se expressa na contemplação de posições divergentes, mas cuja oposição adquire forma a partir de um pano de fundo valorativo mais abrangente, como o imaginário democrático e, na perspectiva estabelecida por esse artigo, um sistema específico de direitos fundamentais. A distinção, portanto, não pode ser estabelecida nesta questão em termos estritos da distinção amigo/inimigo, mas entre aquelas identidades políticas que provisoriamente integram uma 
assemblage e as que colocam em risco as suas bases. A relação de oposição, então, é repensada em termos mais positivos.

O principal aspecto dessa abordagem foi estabelecido no decorrer deste artigo e é importante que seja recapitulado: o significado dos direitos fundamentais, não obstante a sua positivação e as interpretações estabelecidas pela jurisprudência e doutrina, é essencialmente contestável do ponto de vista político (CONNOLLY, 2008d). Ao menos duas consequências significativas podem ser apontadas: primeiro, o significado desses conceitos, longe de estabelecidos e pacificados, emerge em meio a práticas jurídicas variadas, como também os mencionados conflitos políticos; o segundo, por sua vez, implica na rejeição de qualquer lugar transcendente por meio do qual se pode fixar um significado definitivo para cada um dos direitos fundamentais, um que resiste às sucessivas formas de apropriação e aos diferentes contextos em que essas apropriações ocorrem (PATTON, 2014, p. 223 e ss).

Essa compreensão imanente dos direitos fundamentais permite enxergá-los como elementos estratégicos que não apenas suscetíveis às diferentes redefinições, como também agrega, compõe e permite a transformação das demandas políticas a que estão associados (PATTON, 2014, p. p 235 e ss). Um direito fundamental à moradia adquire significados distintos quando utilizado como elemento de justificação de uma decisão judicial e quando é mobilizado por movimentos sociais que buscam um reconhecimento institucional para as suas demandas políticas mediante proteção estatal (SILVA, 2006, p. 30 e ss).

A estrutura normativa do direito pode ser percebida como tal nas situações mencionadas, mas o modo como se recorre aos direitos traz à tona uma série de elementos contextuais amplamente distintos. A motivação do movimento permite uma confrontação com o status quo, no sentido da insatisfação das demandas por moradia e das circunstâncias precárias que vão proporcionar significado a essas demandas. Para além de sua compreensão em termos de garantias, os direitos fundamentais são, neste segundo cenário, estrategicamente mobilizados para confrontar um conjunto de forças que concorrem para a manutenção de uma circunstância de destituição para os diferentes indivíduos. Nesta direção os direitos fundamentais adquirem importância estratégica enquanto elementos que fomentam a conexão entre grupos diversos que possuem problemas associados a agressões ou restrições aos seus direitos de moradia. Uma vez que esses elementos se encontram inseridos no diploma constitucional, eles passam a representar um referencial normativo abrangente, cujo reconhecimento de sua existência independente de qualquer perspectiva político-ideológica das partes conflitantes. 
É sempre possível que a esse direito fundamental seja oposto um outro, como o direito à proteção da propriedade privada, mas o importante é que um tensionamento político mais circunstancial passa a ser exprimido em uma linguagem mais abrangente e que contempla todos os envolvidos. Esse tensionamento, conforme o apontado em seções precedentes, contribui não somente para a abertura de outras possibilidades estratégicas referente aos usos dos direitos fundamentais, como explora um panorama de significados que esses direitos podem ter. $\mathrm{Na}$ perspectiva das diferentes lutas políticas minoritárias, onde frequentemente a legitimidade das demandas se encontra em disputa, ou mesmo prontamente contestada, esse tensionamento é importante.

O respeito agonístico pode contribuir para o desenvolvimento dessa tensão na medida em que, cultivando uma interdependência partidária, permite a construção de conexões entre atores diferentes a partir de semelhanças valorativas e ideológicas mais abrangentes, dentre as quais pode figurar o respeito pelos direitos fundamentais, pelos valores democráticos e, também, uma visão mais ampla da organização social. As preferências e avaliações subjetivas de cada grupo são traduzidas em uma linguagem com pretensões universalizantes. Essa transição das demandas políticas para um sistema de direitos é pontuada por Paul Patton da seguinte forma:

\begin{abstract}
...ao se postular que alguma maneira de agir ou de ser tratado é um direito implica em postular algo mais próximo a um fato empírico do que um juízo meramente subjetivo de valor ou preferência. Daí o recurso a uma linguagem da descoberta ao se falar sobre os direitos: as pessoas, via de regra, se referem a uma confirmação de que um determinado grupo possui certos direitos ou ao reconhecimento desses direitos pelo Direito, como se os direitos em questão existissem independentemente de sua institucionalização nos sistemas do direito (PATTON, 2014, p. 235). ${ }^{11}$
\end{abstract}

Patton está, de certa maneira, assinalando o caráter performativo que reveste as demandas políticas ancoradas nas reivindicações de direitos: no momento em que os direitos são enunciados, diferentes elementos contextuais, como valores coletivos e expectativas políticas, estabelecem um processo de apriorização no qual os direitos reivindicados precisam ser reconhecidos, ao invés de criados. A criação implica no reconhecimento do caráter contingente das demandas e dos próprios direitos, ou seja, isso significa pensá-los como frutos de um novo panorama histórico, ou seja, o protesto em si atua em um registro simbólico, não

\footnotetext{
${ }^{11}$ No original: “...claiming that some way of acting or being treated is a right amounts to claiming that it is more like an empirical fact than a merely subjective value judgment or preference. Hence the common recourse to the language of discovery in speaking about rights: people often refer to the acknowledgment that a particular group possesses certain rights or the recognition of those rights by the law, as though the rights in question exist in some sense independently of their institutionalization in systems of law."
} 
sendo completamente redutível ao instrumental, como uma ação orientada a um fim préestabelecido (ALEXANDER, 2017). Por outro lado, o efeito de apriorização impõe ao status quo que as reivindicações sejam reconhecidas como decorrentes dos compromissos e/ou dos pressupostos políticos já compartilhados pela comunidade.

No tocante às lutas pelos direitos das mulheres, o efeito de apriorização chama atenção para a postulação de uma desigualdade constitutiva referente às formas de disposição das oportunidades e dos espaços concedidos aos gêneros. Reivindicar direitos, neste ponto, não se restringe à formulação de novas normas jurídicas e ou da superação das limitações institucionais que obstruem, ou mesmo inviabilizam, o acesso das mulheres ao mercado de trabalho, a posições políticas mais significativas ou a uma maior autonomia estendida ao seu ambiente familiar doméstico. As demandas envolvem todos esses pontos, mas em última instância lidam com algo mais profundo e persistente, a saber, a reformulação do imaginário político que envolve esses direitos: eles, os direitos, então, apontam os caminhos e os itinerários para se alcançar esse objetivo estratégico mais abrangente. Discutindo a problemática dos Care Rights, os direitos dos cuidadores, Anja Eleveld traz à tona essa dimensão mais abrangente da reivindicação dos direitos, ou seja, a maneira como ela transforma também as relações sociais subjacentes ao campo a que essa demanda se dirige:

...a atividade de demanda dos direitos deve ser compreendida como uma prática
democrática que abre a possibilidade de um engajamento político. Isso significa que
a demanda das mulheres aos direitos de cuidado não necessariamente contempla a
produção e o reforço daquilo que é tomado como 'natural' (ie. mulheres como
cuidadoras). Pelo contrário, a demanda pelos direitos é vista como contribuindo para
a participação política e como parte das práticas de liberdade democráticas. Em
contraste com uma percepção mais instrumental dos direitos, então, a demanda pelos
direitos não são ou não são exclusivamente compreendidas como meios (i.e direitos
de cuidado) para alcançar certos objetivos (a liberdade das mulheres), mas
predominantemente como prática que permite a compreensão dos relacionamentos
entre diferentes cidadãos visíveis ao mesmo tempo em que re-imagina esses
relacionamentos (ELEVELD, 2015, p. 84 ). ${ }^{12}$

A dimensão performativa das reinvindicações jurídicas, para além de sua eventual incorporação ao ordenamento jurídico vigente, é também importante para destacar, ou mesmo contestar, as pretensões de naturalização dos comportamentos e dos corpos que se encontram

\footnotetext{
${ }^{12}$ No original: "...the activity of rights claiming must be understood as a democratic practice which opens up the possibility of political engagement. This means that women's claims to care rights do not necessarily involve the production and reinforcement of that which is taken to be 'natural' (ie. women as caregivers). On the contrary, rights claims are seen as contributing to political participation and as part of democratic freedom practices. In contrast to the more instrumental perception of rights, then, rights claims are not or not exclusively understood as a means (i.e. care rights) to achieve certain ends (freedom of women), but predominantly as a practice which makes the understandings of relationships between different citizens visible, while at the same time re-imagining these relationships."
} 
reproduzidas em áreas específicas do social. No tipo de reivindicação jurídica apontada por Eleveld, os care rights, o âmbito do trabalho doméstico surge como um dos principais espaços de prática nos quais as relações assimétricas tendem a se desenvolver, incluindo a naturalização da figura feminina como uma "cuidadora natural." A demanda política por mais direitos, neste panorama, para além de propor uma expansão daqueles que já se encontram estabelecidos, também tem o potencial de reconsiderar as relações sociais presentes e um certo caráter assimétrico dessas relações que tende a promover novas formas de subjugação e dominação.

É preciso reiterar, neste momento, um ponto destacado nas seções precedentes: abordar os direitos fundamentais nessa perspectiva envolve um processo contínuo de reinserção e transformação desses direitos a partir de sua inserção em contextos outrora impensáveis ou imprevistos. Se eles são compreendidos em termos de suportes institucionalizados, ou seja, revestem as demandas políticas de uma linguagem apriorística, com pretensões universalizantes, o significado mesmo de cada direito fundamental é também expandido, deslocado ou redefinido em meio ao caráter performativo da reivindicação jurídica. Isso implica uma maneira específica de se abordar a temporalidade dessa reivindicação: o presente do ato é ao mesmo tempo uma abertura para um futuro indefinido, contingente e continuamente postergado.

Inscrevendo essa temática a partir do arcabouço teórico proposto por Connolly, pode-se desenvolver uma conexão produtiva entre o respeito agonístico, as assemblages e os direitos fundamentais. Na medida em que as identidades constitutivas das assemblages são estabelecidas a partir de relações diferenciais, segue-se que a estabilização dessa formação, ou seja, a sua permanência, depende da maneira como as diferentes identidades são organizadas em meio a um outro corpo que não só lhe é distinto, como pode se traduzir em uma relação de oposição. O respeito agonístico exige não apenas uma disposição de tolerância entre as identidades constitutivas de uma mesma assemblage, como referenciais que extrapolem os projetos específicos de cada uma das suas partes: são esses referenciais que vão permitir uma agregação mais consistente das assemblages.

No arcabouço teórico proposto por essa pesquisa, os direitos fundamentais são situados como esses referenciais que transcendem aos projetos particulares. A pesquisa destaca, porém, que essa perspectiva de transcendência não se encontra de maneira alguma desarticulada das circunstâncias específicas que envolvem os impasses e as lutas políticas de cada grupo, a exemplo da compreensão usual que se tem das concepções metafísicas de justiça ou de direito natural. O raciocínio é o contrário: a transcendência dos direitos fundamentais, no que diz 
respeito à composição das assemblages, reside na sua aceitabilidade mais abrangente, por sua vez decorrente de sua inserção nos ordenamentos jurídicos e/ou de sua presença em outros contextos institucionalizados.

Enquanto conjunto de atitudes e disposições que promovem a tolerância e abertura sem, porém, encontrar-se dissociada do potencial de conflito que envolve as variadas relações sociais, esta pesquisa sustenta que o respeito agonístico pode promover deslocamentos e apropriações dos direitos fundamentais a partir de sua inscrição em outros imaginários políticos que não aqueles compartilhados pelo status quo. É neste ponto que se pode ser explorado o potencial político desses direitos a partir dessa interseção entre o presente e o futuro, entre o que está enraizado nas dinâmicas institucionais presentes e os diversos usos que ainda não foram contemplados ou cultivados.

O potencial sinaliza a abertura, a abrangência e a incompletude que reveste o significado estabelecido desses direitos: essa insuficiência, ou, por assim dizer, essa impossibilidade de fechamento completo dos direitos fundamentais é que os tornam tão importantes para a manutenção das assemblages. Sendo abertos, seus usos e sentidos podem ser continuamente redefinidos, tendo como base tanto o conjunto de demandas políticas em questão, como o imaginário político, ou até imaginários políticos, que envolvem essas demandas políticas e, em certo sentido, também as fomenta.

Diante dos desafios e problemas que emergem da pluralização que se desenvolve em meio às democracias liberais contemporâneas, a assemblage se mostra um conceito estratégico importante. No decorrer desta pesquisa, mostrou-se que é válido pensar a tolerância para além de uma concepção essencialista e de que maneira os direitos fundamentais podem ser relevantes neste panorama. A tolerância só pode existir a partir de uma negociação contínua e sempre incompleta entre as relações diferenciais estabelecidas entre as identidades ao mesmo tempo em que se demarca o pano de fundo em comum a todas elas, o que passa pela composição das assemblages. Os direitos fundamentais constituem parte do referencial mais abrangente, extrapolando os limites mais estreitos dos projetos de cada identidade política específica.

Uma vez que a determinação das assemblages implica na constituição de um exterior, ou seja, da imposição de um limite entre as identidades políticas que partilham dos referenciais abrangentes de uma assemblage e aqueles que não se encontram nessa situação, o significado dos direitos fundamentais é politicamente colocado em disputa. Uma assemblage que se desenvolve no espectro progressista da política, provisoriamente composta pelo movimento feministas, LGBT, étnicos, dos trabalhadores, dos sem-terra e dos sem-teto, vai desenvolver 
estrategicamente uma visão específica dos direitos fundamentais que vai colidir com aquela que é esboçada por uma outra assemblage, desta vez marcada por grupos que integram os diferentes interesses (financeiros e culturais) do status quo. O respeito agonístico, então, surge tanto como um conjunto de virtudes que proporcionam uma maior consistência interna às assemblages, mas também como disposição a uma problematização contínua por meio de uma abertura caridosa com aquilo que se nega e se opõe, representando ao mesmo tempo o céu e o inferno da convivência democrática.

\section{CONCLUSÃO}

O objetivo desse artigo foi o de desenvolver uma relação entre as demandas políticas e os direitos fundamentais tendo como base o conceito de pluralismo a partir da teoria política de William E. Connolly. Uma razão para se recorrer a essa abordagem é a de que ela fornece subsídios significativos para que se possa pensar a maneira como os direitos fundamentais podem contribuir de maneiras importantes para a constituição das identidades políticas no contexto das democracias contemporâneas. A temática do pluralismo é desenvolvida em paralelo com a expansão e, por vezes, ressignificação, dos direitos fundamentais em meio às diferentes lutas que marcam o cotidiano político das sociedades democráticas.

Os direitos fundamentais são pensados tanto como consequências, ou seja, reflexos dessas lutas, como também parte das condições que permitem a expansão e o reconhecimento institucional das demandas políticas dos grupos e movimentos. Desta maneira, as lutas políticas não somente redefinem o sentido desses direitos, como vão possibilitar o surgimento de outros direitos que ainda não foram estabelecidos, mas que dialogam com as necessidades e os anseios dos atores políticos. Esclarecer a maneira como os direitos fundamentais estavam sendo compreendidos, e a partir de quais preocupações, foi o objetivo da primeira seção do artigo.

Na segunda seção, a perspectiva adotada neste trabalho, a teoria política de William E. Connolly, é destrinchada tendo como fio condutor a problemática do pluralismo no âmbito das democracias contemporâneas. Essa abordagem é importante porque, ao mesmo tempo em que explora a constituição das identidades políticas em meio aos diferentes focos de conflito que emergem no tecido social, também permite pensar o lugar de elementos presentes nas estruturas sociais, como os direitos fundamentais, na composição das demandas dos diferentes grupos. Desta maneira, a dimensão política dos direitos fundamentais é inserida e abordada em meio aos múltiplos conflitos identitários e suas demandas políticas concorrentes. 
Na terceira e última seção, é desenvolvido o cerne da argumentação deste artigo a partir da teoria de Connolly, já apresentada na segunda seção: os direitos fundamentais operam tanto como condicionadores institucionais das transformações políticas do espaço social, como também são reflexo, ou seja, consequência dessas transformações. A cada novo conjunto de direitos fundamentais e/ou formação de um foco de conflito, os direitos fundamentais já estabelecidos podem ser repensados em seus sentidos e extensões. Essa relação circular tende a uma redefinição incessante dos limites e características das democracias liberais, fortalecendo e ampliando as tendências de inclusão ao mesmo tempo em que expõe as circunstâncias de opressão e dominação de certas relações sociais. Revela-se, deste modo, o potencial político e criativo dos direitos fundamentais para o contínuo fortalecimento do imaginário democrático e a redefinição contínua dos valores que lhe são subjacentes. Tolerância, igualdade e liberdade adquirem novos contornos, perdem certas características ao adquirirem outras: cada circunstância conflituosa traz consigo a possibilidade de uma reconsideração radical da tradição democrática por meio da apropriação discursiva realizada por cada uma das partes.

Em conformidade com os pressupostos da teoria política de Connolly, nenhum desses valores dispõe de definições estabelecidas por posições que transcendam os contextos sóciopolíticos que os envolvem: o caráter elusivo e precário do significado desses valores decorre, dentre outras razões, de uma compreensão estritamente imanente da política que norteia a perspectiva do teórico. Uma abordagem como essa permite dissociar os significados institucionalizados de cada um dos direitos fundamentais, a exemplo daqueles que recorrentemente se fazem presentes na fundamentação das decisões judiciais, do seu potencial político disruptivo e experimental.

\section{REFERÊNCIAS}

ALEXANDER, Jeffrey C. A Tomada do Palco: Performances Sociais de Mao Tsé-Tung a Martin Luther King, e a Black Lives Matter Hoje. Sociologias, v. 19, n. 44, 2017.

ALVAREZ, Silvina. Pluralism and the Interpretation of Women's Human Rights. European Journal of Women's Studies, v. 16, n. 2, pp. 125-141, 2009. DOI: 10.1177/1350506808101762.

BURITY, Joanildo A. Religião, Política e Cultura. Tempo Social: Revista de Sociologia da USP, v. 20, n. 2, pp. 83-113, nov./2018.

CONNOLLY, William E. Agonism and Democracy. In: CHAMBERS, Samuel A.; CARVER, Terrell (Eds.). William E. Connolly: Democracy, Pluralism and Political Theory. London: Routledge, 2008, p. 174-206. 
CONNOLLY, William E. Agonism and Liberalism. In: CHAMBERS, Samuel A.; CARVER, Terrell (Eds.). William E. Connolly: Democracy, Pluralism and Political Theory. London: Routledge, 2008, p. 148-173.

CONNOLLY, William E. An Ethos of Engagement. In: CHAMBERS, Samuel A.; CARVER, Terrell (Eds.). William E. Connolly: Democracy, Pluralism and Political Theory. London: Routledge, 2008c. pp. 231-253.

CONNOLLY, William E. Deep Pluralism. In: CHAMBERS, Samuel A.; CARVER, Terrell (Eds.). William E. Connolly: Democracy, Pluralism and Political Theory. London: Routledge, 2008, p. 85-104.

CONNOLLY, William E. Essentially Contested Concepts. In: CHAMBERS, Samuel A.; CARVER, Terrell (Eds.). William E. Connolly: Democracy, Pluralism and Political Theory. London: Routledge, 2008, p. 257-279.

CONNOLLY, William E. The Ethos of Democratization. In: CRITCHLEY, Simon; MARCHART, Oliver (Eds.). Laclau: A Critical Reader. London: Routledge, 2004, p. 167-181.

CONNOLLY, William E. The Ethos of Pluralization. Minneapolis: University of Minnesota Press, 1995.

CORNELL, Drucilla. At the Heart of Freedom: Feminism, Sex, and Equality. Princeton, New Jersey: Princeton University Press, 1998.

DELANDA, Manuel. A New Philosophy of Society: Assemblage Theory and Social Complexity. London: Bloomsbury Academic, 2019.

DELANDA, Manuel. Assemblage Theory. Edinburgh: Edinburgh University Press, 2016.

DOUZINAS, Costas. Oubliez Critique. Law and Critique, v. 16, pp. 47-49, 2005. DOI: 10.1007/s10978-005-4907-8.

DOUZINAS, Costas. The End of Human Rights: Critical Legal Thought at The Turn of the Century. Oxford: Hart Publishing, 2000.

ELEVELD, Anja. Claiming Care Rights as a Performative Act. Law and Critique, v. 26, pp. 83-100, 2015. DOI: 10.1007/s10978-014-9145-5.

LEFORT, Claude. Democracy and Political Theory. Oxford: Polity Press, 1988.

MAVELLI, Luca. Beyond Secularism: Immanence and transcendence in the political thought of William E. Connolly. In: FINLAYSON, Alan (org.). Democracy and Pluralism: The Political Thought of William E. Connolly. London: Routledge, 2009, p. 144-164.

MOUFFE, Chantal. Democracy, Human Rights and Cosmopolitanism: an agonistic approach. In: DOUZINAS, Conor; GEARTY, Conor (Eds.). The Meanings of Rights: The Philosophy and Social Theory of Human Rights. Cambridge: Cambridge University Press, 2014, p. 181-192. 
MOUFFE, Chantal. On the Political. London: Routledge, 2005.

PARTHEMOS, George S. Contemporary Juristic Theory, Civil Rights and American Politics. Annals of the American Academy of Political and Social Science, v. 334, n. 1, 1962, pp. 95107.

PATTON, Paul. History, normativity, and rights. In: DOUZINAS, Conor; GEARTY, Conor (Eds.). The Meanings of Rights: The Philosophy and Social Theory of Human Rights. Cambridge: Cambridge University Press, 2014, p. 233-250.

SILVA, Virgílio Afonso da. A Evolução dos Direitos Fundamentais. Revista Latino-Americana de Estudos Constitucionais, v. 6, pp. 541-558, 2005.

SILVA, Virgílio Afonso da. O conteúdo essencial dos direitos fundamentais e a eficácia das normas constitucionais. Revista de Direito do Estado, v. 4, pp. 23-51, 2006.

VALENTINE, Jeremy. Time, Politics and Contingency. In: FINLAYSON, Alan (org.). Democracy and Pluralism: The Political Thought of William E. Connolly. London: Routledge, 2009, p. 203-220.

WENMAN, Mark. William E. Connolly: Pluralism without Transcendence. British Journal of Politics and International Relations (BJPIR), v. 10, pp. 156-170, 2008. DOI: 10.1111/j.1467856x.2007.00307.x.

\section{DADOS DA PUBLICAÇÃO}

Categoria: artigo submetido ao double-blind review.

Recebido em: 21/04/2021.

Aceito em: 25/11/2021. 